\title{
Relatos E REFLEXÕES SOBRE AS AÇÕES DO PÓlO ARTE NA ESCOLA DA Universidade Federal do Paraná
}

\section{Report and reflections about the actions of the Programa Arte na Escola - UFPR}

\author{
Ana Maria Petraitis Liblik
}

\section{RESUMO}

\begin{abstract}
Este artigo relata as ações extensionistas do pólo UFPR do Programa Arte na Escola. Uma breve reflexão sobre estas ações com vista à integração do tripé graduação - pesquisa - extensão, da nossa universidade. Perspectivas sobre as ações futuras e a sua importância para a comunidade externa.
\end{abstract}

Palavras-chave: Ensino de Arte; ações extensionistas.

\begin{abstract}
This paper reports the extensionists actions of the Program Arte na Escola/ UFPR. A short reflextion over these actions regarding the integration of the activities of the tripod: graduation - extension and research, of our university. Perpectivs about the future actions and its importancy for the external community.

Keywords: art teaching; extensionist activities.
\end{abstract}

\section{RESUMEN}

Este artículo describe las acciones extensionistas del polo UFPR del Programa Arte na Escola. Es un breve relato de las acciones para la integración de las actividades de trípode graduación, extensión y pesquisa de nuesta universidad, con vistas a las perspectivas de acciones futuras y su importancia para la comunidad externa.

Palabras-clave: enzenanza del arte; actividades de extensión.

\section{Para começo de conversa}

Final de ano e final de semestre, correria natural de pequenas ações que, ao se organizar em conjunto, encerram o trabalho de professores, alunos e convidados. São trabalhos e provas corrigidos, listagens com freqüências $e$ conceitos lançados, notas encerradas para o ano ou semestre letivo que finda, relatórios escritos $e$ apresentados às instâncias superiores.

Ao mesmo tempo em que isto acontece, uma saraivada de idéias se compõe e, efervescente, lança tentáculos em direção ao futuro. São os novos projetos que tomarão forma durante as férias, para as novas ações, para o ano ou semestre vindouro.

\footnotetext{
Doutora em Educação (USP). Professora do Departamento de Teoria e Prática do Ensino do Setor de Educação da Universidade Federal do Paraná, Rua General Carneiro, 460 - \# 511 - Curitiba, PR - ampliblik@UFPR.br - Coordenadora do pólo UFPR artenaescola@UFPR.br
} 
A cada ano que passa, esta é como uma rotina natural: o que "deu certo" se mantém e o que apresentou algumas falhas, algumas lacunas, pensa-se novamente e se refaz o percurso organizando de outra forma as ações. Projetos extensionistas, em sua maioria, são assim projetados.

Uma universidade se estrutura a partir de um tripé bem conhecido: ensino, pesquisa $e$ extensão. Enquanto o ensino é como que uma constante obrigatória e pouco valorizada, a pesquisa tem o status de elite. Pesquisar-ensinar deveria ser o percurso natural de qualquer professor universitário, para não dizer de qualquer profissional da Educação comprometido consigo e com a comunidade.

Entretanto, a realidade é bem mais cruel do que parece: nas universidades públicas a pesquisa, até por uma questão de injeção de verbas federais, apresenta-se como um "degrau" acima do ensino. E neste cenário capenga, a extensão quase desaparece nas ações universitárias. Em instituições públicas, difícil decisão a de priorizar uma das três ações em detrimento das outras...

Como a docência é obrigatória e a pesquisa também, a extensão fica relegada, na maioria dos casos, a uma gaveta de projetos pensados e não realizados. Há uma via de mão dupla, um ciclo que se repete, mas em forma de espiral. Da extensão para a graduação e depois para a pesquisa, $e$ da pesquisa novamente para a graduação e/ou a extensão. Enquanto a graduação é intermediária da relação entre o Ensino Médio e a formação profissional superior, a pesquisa é a que permite aos docentes aperfeiçoar seus conhecimentos e fazê-los avançar para que se adaptem e se constituam como base para novas construções teóricas. Uma teoria ou se refuta ou se amplia, ou então, se cria uma nova. E é nas universidades, com a pesquisa, que isto acontece.

O ensino é o que melhor representa o que a comunidade acredita ser e espera da uni- versidade. A graduação é o que todos desejam alcançar sendo que a pós-graduação - tanto strictu quando latu senso, ainda é para poucos.

A extensão, por outro lado, estende seus braços para a comunidade não necessariamente acadêmica. São grupos de estudo, projetos, cursos, palestras, ações pontuais e outras continuadas, que apresentam a quem estiver interessado, parte da pesquisa realizada pelos professores da universidade associando assim um saber a um fazer.

Parece fácil pensar em atividades extensionistas assim, em termos de pessoas $e$ materiais. Porém a organização e a efetiva realização das ações dependem muito mais de projetos pessoais de vida e de crenças do que de outros mecanismos. Extensão sem profissionais comprometidos e sem suporte logístico e afetivo torna-se quase uma utopia. É necessária uma estrutura mínima para que ela aconteça, mas não basta haver um local, uma sala, telefone e computador com Internet, professor responsável e, quem sabe, bolsistas. Além de tudo isto é preciso estabelecer parcerias - internas e externas à universidade - que auxiliem o coordenador a realizar os projetos que ele propõe. Uma destas parcerias é a realizada com o Instituto Arte na Escola de São Paulo (IAE) e é desta possibilidade que este artigo trata.

O objetivo do Instituto Arte na Escola sempre foi capacitar professores de ensino básico para o ensino de Artes, sendo num primeiro momento, artes visuais, e para a produção de materiais como subsídios nessa tarefa. Além de textos (livros), há vídeos, pastas com imagens fixas denominadas arte br, e dvd's, tudo para empréstimo aos professores que nos procuram. Como é sabido que este material por si só não resolve o problema, o IAE sugere que sejam organizados grupos de estudo e outras atividades extensionistas para o efetivo entendimento do uso dos materiais por ele produzidos. 


\section{As ações extensionistas}

O convênio assinado entre a Universidade Federal do Paraná e o Instituto Arte na Escola prevê estas ações extensionistas. O objetivo principal do Programa Arte na Escola no pólo UFPR (assim como o dos outros 53 pólos espalhados por 24 estados brasileiros e o distrito federal) é estudar as diferentes possibilidades de ensino de Artes nos mais diversos graus de escolarização e auxiliar professores a implementá-las. Projetos extensionistas trabalham desta maneira: não é apenas um ensinar, mas principalmente, é construir juntos, universidade e comunidade, saberes específicos para o ensino de Artes. Os pólos têm atividades organizadas a partir dos objetivos do IAE, da formação do coordenador do pólo e das demandas da comunidade local. Alguns pólos trabalham com conteúdos de artes visuais, outros com a linguagem da música, do teatro e da dança. Outros pólos voltam-se, além das discussões sobre as diferentes linguagens artísticas, para a formação continuada de professores do ensino básico (sem formação específica em Artes). Como isto é feito?

Novamente a imagem de uma espiral se faz presente e explicita como isto acontece. Estudar, estudar muito, pesquisar, (re) elaborar idéias e conceitos e concretizá-los. Pesquisadores e professores em ação contínua organizando encontros, sugerindo textos, apresentando estratégias. A troca entre parceiros é salutar e acontece constantemente e a cada ano por meio de produções textuais que podem ou não ser apresentadas em eventos. A publicação destas pesquisas faz parte do mundo acadêmico e sua socialização impele a novas organizações mentais que podem ou não gerar novas idéias $e$ novas ações. $\mathrm{O}$ ciclo se completa a cada ano que termina, com a reflexão do acontecido $e$ com a preparação do que vai acontecer no próximo ano.

Vejamos então o que foi feito pelo pólo UFPR desde o seu (re) começo em 2004, quando da assinatura de um novo convênio com o Instituto Arte na Escola de São Paulo.

\begin{tabular}{|l|l|l|l|l|}
\hline \multicolumn{5}{|c|}{ Quadro de atividades realizadas } \\
\hline ano & título & Mês /semestre & $\begin{array}{l}\text { Número de } \\
\text { professores } \\
\text { atendidos }\end{array}$ & Observações \\
\hline 2004 & $\begin{array}{l}1 . \quad \text { Lançamento do } \\
\text { material arte br. }\end{array}$ & junho & 880 & $\begin{array}{l}\text { Presença } \\
\text { do Sr. } \\
\text { Reitor }\end{array}$ \\
\cline { 2 - 5 } & $\begin{array}{l}\text { 2. Capacitação } \\
\text { para uso do material } \\
\text { arte br. }\end{array}$ & $\begin{array}{l}2^{\circ} \text { semestre } \\
\text { 1. Inauguração } \\
\text { das instalações da } \\
\text { sala do pólo UFPR, } \\
\text { com a apresentação } \\
\text { do Quarteto de cordas } \\
\text { didático. }\end{array}$ & $\begin{array}{l}\text { Entrega de } \\
\text { uma pasta } \\
\text { para cada } \\
\text { professor. }\end{array}$ \\
\hline $\begin{array}{l}\text { 2. I Ciclo de junho } \\
\text { e entendendo as } \\
\text { possibilidades de } \\
\text { utilização do material } \\
\text { do Projeto Arte na } \\
\text { Escola. }\end{array}$ & 0900 & $\begin{array}{l}\text { Presença } \\
\text { do Sr. } \\
\text { Reitor }\end{array}$ \\
\hline
\end{tabular}




\begin{tabular}{|c|c|c|c|}
\hline & $\begin{array}{l}\text { 3. Doação de } 800 \\
\text { publicações de Arte } \\
\text { para a Secretaria de } \\
\text { Cultura do Estado do } \\
\text { Paraná }\end{array}$ & & $\begin{array}{lr}\text { Dois exemplares } & \text { para } \\
\text { cada biblioteca de esco } & \text { las } \\
\text { do Estado do Paraná. } & \end{array}$ \\
\hline & $\begin{array}{l}\text { 4. Quarteto } \\
\text { Cordas didático }\end{array}$ & $\begin{array}{l}\text { Março a } \\
\text { novembro }\end{array}$ & $\begin{array}{l}16 \text { concertos - com a } \\
\text { presença de } 35 \text { alunos e } \\
\text { dois professores cada. }\end{array}$ \\
\hline \multirow[t]{4}{*}{2006} & $\begin{array}{l}\text { 1. II Ciclo de } \\
\text { vídeos } \\
\text { A rte e História da } \\
\text { imagens no Ensino da } \\
\text { Arte. }\end{array}$ & $21 / 03$ a $13 / 06$ & 10 \\
\hline & $\begin{array}{l}\text { 2. III Ciclo } \\
\text { vídeos de } \\
\text { estudos em Artes, a } \\
\text { partir da videoteca } \\
\text { Arte na Escola. }\end{array}$ & $16 / 08$ a $22 / 11$ & 16 \\
\hline & $\begin{array}{l}\text { 3. Ensino } \\
\text { Geometria nas Séries } \\
\text { Inicia is do Ensino } \\
\text { Fundamental: } \\
\text { conexões com o } \\
\text { contexto artístico. }\end{array}$ & $16 / 08$ a $22 / 11$ & 12 \\
\hline & $\begin{array}{l}\text { 4. Quarteto } \mathrm{de} \\
\text { Cordas didático }\end{array}$ & $\begin{array}{l}\text { Março a } \\
\text { novem bro }\end{array}$ & $\begin{array}{l}16 \text { concertos - com } \\
\text { presença de } 35 \text { alunos e } \\
\text { dois professores cada. }\end{array}$ \\
\hline \multirow[t]{4}{*}{2007} & $\begin{array}{l}\text { 1. IV Ciclo } \text { de } \\
\text { vídeos }- \text { grupo de } \\
\text { estudos em Artes, a } \\
\text { partir da vide oteca } \\
\text { Arte na Escola. }\end{array}$ & $07 / 03$ a $20 / 06$ & \\
\hline & $\begin{array}{l}\text { 2. Ensino de Geometria } \\
\text { nas Séries Iniciais do } \\
\text { Ensino Fundamental: } \\
\text { conexões com o contexto } \\
\text { artístico. }\end{array}$ & $15 / 08$ a $28 / 08$ & \\
\hline & $\begin{array}{l}\text { 3. Doação de } 800 \\
\text { publicações de Arte para } \\
\text { a Secretaria de Cultura do } \\
\text { Estado do Paraná }\end{array}$ & & $\begin{array}{l}\text { Dois exemplares para cada } \\
\text { biblioteca de escolas do } \\
\text { Estado do Paraná }\end{array}$ \\
\hline & $\begin{array}{l}\text { 4. Quarteto de Cordas } \\
\text { didático }\end{array}$ & $\begin{array}{l}\text { Março a } \\
\text { Novembro }\end{array}$ & $\begin{array}{l}16 \text { concertos - com a presença } \\
\text { de } 35 \text { alunos e dois } \\
\text { professores cada. }\end{array}$ \\
\hline 2007 & \multicolumn{3}{|c|}{$\begin{array}{l}\text { Exposições com a chancela Arte na Escola em espaços culturais da } \\
\text { UFPR } \\
\text { ESPAÇO, TEMPO, ESTRUTURA, ABSTRAÇÃO } \\
\text { DIÁLOGOS ENTRE ARTE E MATEMÁTICA } \\
\text { MusA - Museu de arte da UFPR } \\
26 \text { de junho a } 09 \text { de setembro de } 2007 \\
\text { IV MOSTRA LATINOAMERICANA DE ARTES VISUAIS } \\
\text { MusA - Museu de arte da UFPR } \\
13 \text { de setembro a } 18 \text { de novembro de } 2007\end{array}$} \\
\hline
\end{tabular}




\begin{tabular}{|c|c|c|c|c|}
\hline & \multicolumn{4}{|c|}{$\begin{array}{l}\text { Espetáculos } \\
\text { - DANÇA MONDRIAN } \\
\text { Apresentação do Grupo Tésser a Cia. de Dança da UFPR na } \\
\text { Conferência Inaugural no XI EBRAPEM - Encontro Brasileiro de } \\
\text { estudantes de pós-graduação em Educação Matemática. } \\
\text { CENTRO POLITÉCNICO DA UFPR - SAGUÃO DO PRÉDIO DA } \\
\text { ADMINISTRAÇÃO } \\
07 \text { de setembro de } 2007 \\
\text { Mesas redondas } \\
\text { NARRATIVAS CONTEMPORÂNEAS } \\
\text { FÁBIO MAGALHÃES, MONTSERRAT ALBORES GLEASON } \\
\text { (MÉXICO), JAIME CERÓN (COLÔMBIA), PAULO REIS. } \\
\text { Sala Homero de Barros - Reitoria da Universidade Federal do } \\
\text { Paraná. } \\
13 \text { de setembro de } 2007 \text { as } 15 \text { h } \\
\text { NARRATIVAS CONTEMPORÂNEAS } \\
\text { PAULO REIS, TICIO ESCOBAR ( PARAGUAI), EVA GRINSTEIN } \\
\text { (ARGENTINA) E FERNANDO BINI. } \\
\text { Sala Homero de Barros - Reitoria da Universidade Federal do } \\
\text { Paraná. } \\
13 \text { de setembro de } 2007 \text { as } 18 \text { h } 30 \\
\text { SOBRE A OBRA DE RICARDO CARNEIRO } \\
\text { MusA - Museu de Arte da Universidade Federal do Paraná. } \\
29 \text { de novembro de } 2007 \text { as } 19 \mathrm{~h} \\
\text { Outras atividades } \\
\text { NOITE DE AUTÓGRAFOS } \\
\text { Lançamento do livro BRUGNERA - LUIZ CARLOS } \\
\text { MusA - Museu de Arte da Universidade Federal do Paraná } \\
18 \text { de outubro de } 2007 \text { às } 19 \mathrm{~h}\end{array}$} \\
\hline \multirow[t]{5}{*}{2008} & $\begin{array}{l}\text { 1. Grupo de } \\
\text { Estudos em Artes a } \\
\text { partir da midiateca } \\
\text { Arte na Escola }\end{array}$ & $\begin{array}{l}19 / 03 a \\
25 / 06\end{array}$ & 5 & $\begin{array}{l}\text { Produção de materiais } \\
\text { didáticos }\end{array}$ \\
\hline & $\begin{array}{l}\text { 2. VI Ciclo de } \\
\text { vídeos - grupo de } \\
\text { estudos em Artes, a } \\
\text { partir da videoteca } \\
\text { Arte na Escola. }\end{array}$ & $\begin{array}{l}19 / 03 a \\
25 / 06\end{array}$ & 12 & $\begin{array}{l}\text { Produção de materiais } \\
\text { didáticos }\end{array}$ \\
\hline & $\begin{array}{l}\text { 3. Grupo de } \\
\text { Estudos em Teatro I - } \\
\text { jogos dramáticos para } \\
\text { a sala de aula }\end{array}$ & $\begin{array}{l}19 / 03 a \\
25 / 06\end{array}$ & 12 & \\
\hline & $\begin{array}{l}\text { 4. Grupo de } \\
\text { Estudos em Artes a } \\
\text { partir da midiateca } \\
\text { Arte na Escola }\end{array}$ & $\begin{array}{l}11 / 08 \text { a } \\
28 / 11\end{array}$ & 05 & $\begin{array}{l}\text { Produção de materiais } \\
\text { didáticos }\end{array}$ \\
\hline & $\begin{array}{l}\text { 5. VII Ciclo de } \\
\text { vídeos - grupo de } \\
\text { estudos em Artes, a } \\
\text { partir da videoteca } \\
\text { Arte na Escola. }\end{array}$ & $\begin{array}{l}11 / 08 a \\
28 / 11\end{array}$ & 15 & \\
\hline
\end{tabular}




\begin{tabular}{|c|c|c|c|}
\hline $\begin{array}{l}\text { 6. Grupo de } \\
\text { Estudos em Teatro II } \\
\text { - jogos dramáticos } \\
\text { para a sala de aula }\end{array}$ & $\begin{array}{l}11 / 08 \text { a } \\
28 / 11\end{array}$ & 12 & \\
\hline $\begin{array}{l}\text { 7. Atividades de } \\
\text { Dança para as séries } \\
\text { iniciais do Ensino } \\
\text { fundamental }\end{array}$ & $\begin{array}{l}11 / 08 \text { a } \\
28 / 11\end{array}$ & 12 & \\
\hline $\begin{array}{l}\text { 8. Atividades de } \\
\text { Capoeira para as } \\
\text { séries iniciais do } \\
\text { Ensino fundamental }\end{array}$ & $\begin{array}{l}11 / 08 \text { a } \\
28 / 11\end{array}$ & 12 & \\
\hline $\begin{array}{l}\text { 9. Atendimento a } \\
\text { professores - plantão } \\
\text { semanal }\end{array}$ & $\begin{array}{l}19 / 03 a \\
28 / 11\end{array}$ & $\begin{array}{l}\text { Variá- } \\
\text { vel }\end{array}$ & $\begin{array}{l}\text { O atendimento funciona } \\
\text { como um espaço para } \\
\text { troca de "figurinhas" } \\
\text { entre professores do } \\
\text { ensino básico e a } \\
\text { coordenação do pólo. }\end{array}$ \\
\hline
\end{tabular}

As atividades do pólo UFPR atendem basicamente três linguagens artísticas: Música, Teatro e Artes Visuais, todas encaminhadas para as ações de sala de aula.

Uma primeira reflexão seria sobre o projeto Quarteto de Cordas didático. É uma atividade realizada com alunos do curso de Licenciatura em Música onde eles apresentam para alunos de uma turma de escola pública, e em uma hora/ aula, o que é um quarteto de cordas. O trabalho é feito em uma sala de aula, com no máximo 35 alunos e dois professores e não no auditório da escola para que os alunos possam se aproximar dos instrumentos e dos músicos. Mantivemos esta atividade durante dois anos consecutivos - 2005 e 2006 - e pretendemos retomá-la em 2009, pois a procura é muito grande. A nossa reflexão nos leva a perguntar: como formar ouvintes de música se ela não é apresentada cedo, durante a escolaridade básica dos alunos? A resposta se esta forma de "formar" ouvintes é ou não positiva, só o tempo poderá nos dar.

O Teatro como atividade para a sala de aula é recente em nosso programa. Começou no primeiro semestre deste ano e estamos repetindo no segundo semestre. Há interesse e procura e os participantes são variados. Temos desde professores em formação continuada até alunos de cursos de graduação e filhos de servidores da própria UFPR. A linguagem do Teatro, utilizada na perspectiva dos jogos dramáticos tem muito a acrescentar nas atividades escolares e tem sido uma experiência interessante.

As Artes Visuais são atendidas em diferentes momentos. Temos os Ciclos de vídeo/ dvd que passaram, de uma simples apresentação da fita ou do dvd da midiateca com uma posterior discussão, a grupos organizados de estudos com produção de materiais didáticos. O objetivo de dois destes grupos agora é a publicação dos materiais produzidos.

Um momento interessante e que ainda não está bem explorado, é o atendimento individual a professores. Como o horário à disposição é semanal, há dias em que aparecem para conversar dois ou três professores e em outros, não vem ninguém. Todos até agora tiveram interesse em discutir sobre a própria sala de aula, o que ensinar em Arte e como fazê-lo. Funciona mais como uma ouvidoria do que propriamente um espaço para discussão, mas estes professores retornam e, quem sabe, um dia poderão fazer parte de nossas atividades em grupo de estudos. 
Algumas considerações podem ser feitas a partir do perfil de quem nos procura para as atividades extensionistas. Praticamente $85 \%$ dos professores que freqüentam o pólo pertencem à categoria de professores em formação continuada. Destes, a maioria está em sala de aula e vem à procura de novas possibilidades de ação. Buscam conhecer teóricos mais atuais e participam ativamente das atividades extensionistas por determinado tempo. Novos materiais e outras possibilidades para a sala de aula os atraem e continuamente nos procuram, tanto por e-mail quanto por telefone. Uma parte pequena ainda não assumiu uma classe de alunos e, portanto, ao freqüentar os cursos proporcionados pelo pólo Arte na Escola UFPR, acreditam estar mais bem preparados para o futuro próximo. Há também alunos do curso de Artes Visuais - da nossa própria instituição e de outras da cidade, alunos de outras graduações e muitos professores do Estado do Paraná que fazem parte de um programa denominado PDE - Programa de Desenvolvimento Educacional. Estes últimos, para fazer parte deste programa, passaram por uma rigorosa seleção da Secretaria de Educação do Estado do Paraná e, por terem que freqüentar a universidade, incluem as nossas ações extensionistas em sua grade horária.

Outro fator interessante a ser notado é que o espaço do nosso pólo, assim como deve ser o de outros, serve também como um local de troca de "figurinhas" entre pares. São estratégias compartilhadas, são idéias postas em discussão, são ações que vão para as salas de aula e se renovam a cada encontro que passa.

\section{Conclusões}

Há muito que escrever sobre as ações extensionistas de nossa universidade para o ensino de Artes Visuais. As organizadas e realiza- das pelo pólo Arte na Escola da UFPR são tímidas pelo que poderia ser feito com uma equipe maior de participantes ou com a superação das limitações que uma universidade pública impõe.

Considerando, porém, o que está sendo feito, acreditamos atender positivamente o público que nos procura. Talvez o mais importante, mais significativo nestas nossas ações, seja não o que fazemos, mas a maneira com que isso acontece. No começo entendíamos que bastava "dar receitas prontas" para um público que ainda não sabia o que esperar do projeto. Nem nós sabíamos muito bem o que fazer, era apenas uma intuição acadêmica do que acreditávamos ser o mais adequado para os professores que nos procuravam. Hoje temos, com este mesmo público, muito mais que uma troca de idéias, um compartilhar de saberes que lentamente, mas consistentemente se organiza a partir do que se lê, do que se estuda para passar então a produzir novos saberes em conjunto. Percebemos que agora é uma construção coletiva, um caminhar juntos, mesmo que seja com as dificuldades da construção epistemológica do saber. Consideramos, nos grupos, que não há quem sabe mais, e sim quem sabe diferente. E é no confronto destas diferenças que se possibilita o surgimento de um novo saber. Questionando o respeito pelo outro, entender as diferenças e, conseguindo assim, saber manter esse respeito permite-se e se aceita a tão discutida alteridade. Segundo Gusmão (1997) "a aventura de se colocar no lugar do outro, de ver como o outro vê, de compreender um conhecimento que não é nosso é o que chamamos de alteridade". E é nesta troca entre professores em formação e professores com anos de experiência $e$ a academia que se pautam as ações extensionistas.

A universidade sempre se preocupou em pesquisar e ensinar. A questão da extensão, a ponte entre a academia $e$ a comunidade que origina e sustenta esta instituição, é bem mais recente. Saber para si é importante, mas saber para si e para os outros é sábio e muito mais valioso. 


\section{REFERÊNCIAS}

GUSMÃO, Neusa M. M. Antropologia e educação: origens de um diálogo. Campinas: 1997.

UNIVERSIDADE FEDERAL DO PARANÁ. Relatório do Projeto de Extensão Lançamento do material arte br. Curitiba, 2004.

Relatório do Projeto de Extensão Capacitação para uso do material arte br. Curitiba, 2004.

Relatório do Projeto de Extensão I Ciclo de vídeos - conhecendo e entendendo as possibilidades de utilização do material do Projeto Arte na Escola. Curitiba, 2005.

Relatório do Projeto de Extensão Quarteto de cordas didático. Curitiba, 2005.

Relatório do Projeto de Extensão II Ciclo de vídeos - História da Arte e Leitura de imagens no Ensino da Arte. Curitiba, 2006.

Relatório do Projeto de Extensão III Ciclo de vídeos - grupo de estudos em Artes, a partir da videoteca Arte na Escola. Curitiba, 2006

Relatório do Projeto de Extensão Ensino de Geometria nas Séries Iniciais do Ensino Fundamental: conexões com o contexto artístico. Curitiba, 2006.
. Relatório do Projeto de Extensão Quarteto de cordas didático. Curitiba, 2006.

. Relatório do Projeto de Extensão IV Ciclo de vídeos - grupo de estudos em Artes, a partir da videoteca Arte na Escola. Curitiba, 2007.

. Relatório do Projeto de Extensão Ensino de Geometria nas Séries Iniciais do Ensino Fundamental: conexões com o contexto artístico. Curitiba, 2007.

. Relatório do Projeto de Extensão V Ciclo de vídeos - grupo de estudos em Artes, a partir da videoteca Arte na Escola. Curitiba, 2007.

- Relatório do Projeto de Extensão Grupo de

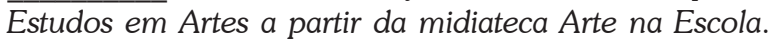
Curitiba, 2007.

- Relatório do Projeto de Extensão Grupo de

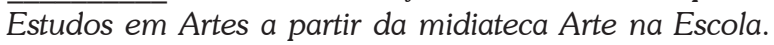
Curitiba, 2008.

. Relatório do Projeto de Extensão VI Ciclo de vídeos - grupo de estudos em Artes, a partir da videoteca Arte na Escola. Curitiba, 2008.

. Relatório do Projeto de Extensão Grupo de Estudos em Teatro I - jogos dramáticos para a sala de aula. Curitiba, 2008.

Texto recebido em 30 jun. 2008. Texto aprovado em 10 set. 2008. 